Original Article

Artigo Original

Maria Isabel Ramos do Amaral ${ }^{1}$ (C) Nádia Giulian de Carvalho² Maria Francisca Colella-Santos ${ }^{1}$ (1)

Keywords Child Hearing

Early Detection

Hearing Tests Auditory Perception

Descritores

Criança

Audição

Detecção Precoce

Testes Auditivos

Percepção Auditiva
Correspondence address:

Maria Isabel Ramos do Amaral

Universidade Estadual de Campinas UNICAMP

Rua Tessália Vieira de Camargo,

126, Cidade Universitária Zeferino

Vaz, Campinas (SP), Brasil, CP 6111, CEP: 13083-887.

E-mail: mamaral@fcm.unicamp.br
Computer-based central auditory

processing screening for school-age children (audBility): an initial investigation

\section{Programa online de triagem do processamento auditivo central em escolares (audBility): investigação inicial}

\begin{abstract}
Purpose: To study an initial version of a new computer-based program for auditory processing screening of school-age children: "audBility." Specifically, the study aimed to analyze performance in individual tasks, level of difficulty per age group, administration time and data management and propose adjustments for a final version to be validated in future research, based on the administration of "audBility" on children with good school performance. Methods: Forty-three school-age children with good school performance were selected. The program assesses hearing skills related to sound localization, competitive dichotic listening, binaural integration, auditory figure-ground, auditory closure, temporal resolution and temporal ordering, as well as a self-perception questionnaire answered by the children. Results: The mean score obtained in the questionnaire was $44.75 \pm 6.3$. Based on the analysis of performance in the individual tasks, improvements were made in the auditory closure and temporal resolution tests and also the research protocol was reduced and defined to adjust to administration time. It was identified a necessity of two separate modules: one for the age groups of 6 to 8 and other for 9 to 12 years, beyond the inclusion of two new versions of the questionnaire that can be answered by teachers and/or parents. Conclusion: The development of audBility is an advance in the area of central auditory processing screening in school-age children. New researches for the validation of audBility are underway, with an increased sample and comparison with the diagnostic battery. The initial results enabled the development of the final version of the protocol to be used in the validation study.
\end{abstract}

\section{RESUMO}

Objetivo: estudar a versão inicial de um novo programa online de triagem do processamento auditivo em escolares: "audBility". A partir da aplicação em crianças com bom desempenho escolar, a pesquisa teve como objetivo específico analisar o desempenho em cada tarefa, nível de dificuldade por faixa etária, tempo de aplicação, gerenciamento dos dados e propor ajustes e melhorias para a versão final, a qual posteriormente deverá ser validada em pesquisas futuras. Método: participaram 43 escolares com idades entre 8 e 11 anos e bom desempenho escolar. O programa avalia as habilidades auditivas de localização sonora, escuta dicótica competitiva (dígitos e dissílabos), integração binaural, figura-fundo, fechamento auditivo, resolução e ordenação temporal, além de um questionário de autopercepção direcionado aos escolares, baseado no instrumento "Scale of Auditory Behaviors." Resultados: o escore médio obtido no questionário foi de $44,75 \pm 6,3$ pontos. A partir do desempenho em cada atividade, foram realizadas melhorias no teste de fechamento auditivo e temporais; redução e definição do protocolo de pesquisa para adequar o tempo de aplicação. Observou-se a necessidade de dois módulos, divididos para crianças na faixa etária de 6 a 8 anos e de 9 a 12 anos, e o acréscimo de duas versões do questionário, direcionados para os pais e professores. Conclusão: o desenvolvimento do audBility é um avanço na área do processamento auditivo e triagem escolar. A validação do audBility está sendo realizada com o aumento da amostra e comparação com a bateria diagnóstica. Os resultados iniciais possibilitaram o desenvolvimento da versão final do protocolo a ser utilizado no estudo de validação.
Study conduct at Departamento de Desenvolvimento Humano e Reabilitação - DDHR, Faculdade de Ciências Médicas - FCM, Universidade Estadual de Campinas - UNICAMP - Campinas (SP), Brazil.

${ }^{1}$ Departamento de Desenvolvimento Humano e Reabilitação, Centro de Investigação em Pediatria, Faculdade de Ciências Médicas - FCM, Universidade Estadual de Campinas - UNICAMP - Campinas (SP), Brasil.

${ }^{2}$ Centro de Investigação em Pediatria, Faculdade de Ciências Médicas - FCM, Universidade Estadual de Campinas - UNICAMP - Campinas (SP), Brasil.

Financial support: Programa Nacional de Pós-Doutorado - PNPD/CAPES and FAPESP (\#2016/23718-2). Conflict of interests: nothing to declare. 


\section{INTRODUCTION}

It is known that a correct analysis and interpretation of auditory information requires anatomical and functional integrity of the auditory system structures, both peripheral and central. Therefore, the efficient analysis of the auditory information depends on the action of several neural mechanisms related to the different auditory abilities, which characterize the "Central Auditory Processing" (CAP) ${ }^{(1-3)}$.

There is consensus that CAP has become a consolidated area of clinical practice and research. Studies in the area seek to deepen knowledge on the central auditory nervous system (CANS) and associated areas, such as the establishment of standardized protocols and validated assessment batteries.

Central Auditory Processing Disorder (CAPD) is defined as a deficit in neural processing of auditory stimuli and may coexist or be associated with changes in language development and/or neurological conditions. In other words, it relates to a dysfunction in CANS that leads to certain hearing difficulties and, consequently, behavioral manifestations ${ }^{(4)}$. Therefore, the early identification and evaluation of children at risk of CAPD is fundamental.

Since there is no single standard gold procedure for diagnosis of CAPD, since 1980s there has been growing research interest in an effective battery directed to central auditory screening ${ }^{(5,6)}$.

Current studies search for interactive and easily accessible tools as a screening method ${ }^{(7,8)}$. The challenge is the need for a battery capable of adequately evaluating all the above-mentioned auditory mechanisms involved in $\mathrm{CAP}^{(9)}$, as well as confirmation of its efficacy through comparison with diagnostic tests. In addition, recent guidelines suggest the need to consider the use of self-perception questionnaires as an important assessment integrated with CAP screening, as they may, when appropriately used, contribute relevant qualitative data to identify behavior risk for CAPD ${ }^{(1,4,10)}$.

The present study aimed to investigate the initial version of a new online program designed for screening hearing skills in school-aged children, called "audBility", and propose adjustments and improvements to its final version. The results were discussed considering task complexity and adjustment to age group, program administration time and comparison of performance by ear in monotonic and dichotic listening tasks. Based on the outcomes herein presented, the final protocol should be studied in different populations in future research, involving subjects with typical or atypical development and samples with confirmed central auditory processing disorder to verify the screening pass/fail reference criteria and obtain validation against the diagnostic battery.

\section{METHODS}

\section{Study design}

This is a descriptive, prospective and cross-sectional study performed at the Audiology Laboratory of the institution where the research was carried out, in partnership with a school of the Campinas Public Education System.

\section{Ethical considerations and sample selection}

This study was approved by the Research Ethics Committee of the institution, under opinion No. 1,538-278/2016. Following the presentation of the research project to the school's educational staff, an invitation letter was sent to the parents, with the additional purpose of presenting the project's activities. The informed consent form was signed by all parents and/or guardians who agreed to participate, as well as by the children.

All children whose parents agreed to their participation were screened. Subsequently, for data analysis, their school performance was individually analyzed through a form answered by the teachers of each class, comprising questions about the students' performance in class and school evaluations, presence or absence of learning difficulties or hearing complaints and relationship with peers. The study considered the results of children who were eligible according to the inclusion and exclusion criteria described below.

\section{Inclusion and exclusion criteria}

The following inclusion criteria were considered: normal otoscopy, bilateral type A tympanometry, presence of ipsilateral acoustic reflexes and good school performance reported by the responsible teacher. A Heine Mini 2000 otoscope was used as well as an Interacoustics MT10 portable device, which allows acoustic immitance measures to be obtained at school, ruling out middle ear conditions. Children with a record of relevant otology conditions, who had undergone speech therapy due to difficulties in oral or written language and with other possible neuropsychomotor developmental disorders were excluded.

\section{Participants}

The sample comprised 43 children aged 8 to 11 (mean 9.6 \pm 1.1 ). Regarding gender, 23 (54.4\%) schoolchildren were girls and $20(46.6 \%)$ were boys.

\section{Preparation of testing material}

In this study, the researchers investigated an initial version of an online program/platform designed as an auditory processing screening battery, called audBility. Technical-scientific meetings were initially held between the group of researchers and the technical team that developed the product with the purpose of adapting the acoustic characteristics/parameters of the hearing tasks and reviewing the self-perception questionnaire, forms of visualizing answers and possibilities for managing collected data. Subsequently, the institution's research group carried out a pilot study with 10 children to check the program's administration conditions and time and the adequate operation of the platform, train the researcher regarding administration and data collection and identify possible errors in the activities available in the battery. Following the first adjustments, the battery was finished and administered as a data collection procedure of the present study.

Below are described the auditory tasks of the online program administered in the present study: 


\section{Self-perception questionnaire based on "Scale of Auditory} Behaviors" on its translated version for European Portuguese - $(\mathbf{S A B})^{(11,12)}$ The original SAB questionnaire comprised 12 sentences concerning hearing difficulties and/or behavior in listening situations in quiet and noisy environments, following instructions, sound localization, attention span and difficulty in learning. The answers given by the children are related to the frequency with which the event or difficulty occurs and there are five closed alternatives with a score attributed to each one, namely: frequent (1 point), often ( 2 points), sometimes ( 3 points), seldom ( 4 points) and never (5 points). The score obtained ranges from 12 to 60 points. Platform consisted of transforming the affirmative phrases into direct questions with more accessible language for the participants understanding and including an "example situation" prior to each question in order to contextualize the auditory behavior in the context of daily life for the child and facilitate comprehension. It was calculated the final mean score and standard deviation of the sample performance, and also considered the reference criterion of the sample based on the mean obtained subtracted from a standard deviation.

2. Auditory tasks: The initial version of the CAP screening battery was composed of eight tasks designed to evaluate the same auditory mechanisms assessed in validated tests of the diagnostic battery. Therefore, the activities aim to screen such skills based on tasks that are similar but differ in specific parameters, acoustic stimuli and administration time. The initial version of the program was administered and the activities of that version are detailed below:

1 - Sound localization: 10 situations in which the child hears different sounds and must choose the correct direction regarding the localization of the target stimulus (right, left or above/behind). The sounds are of daily events like mosquitoes buzzing, paper tearing and others. This task was adapted following the principles of the Five-Direction Localization Test ${ }^{(13)}$. that aims to obtain information on binaural interaction by evaluating the physiological mechanism of discrimination of the sound source.

2 - Dichotic Digit Test (binaural integration): 10 sequences in which the child hears fours numbers, two in the right ear and two in the left ear, concomitantly. The child should respond by repeating and/or pointing on the screen the four numbers heard, regardless of the order of listening. The screen will always display as options all numbers from 1 to 9 for selection of the four numbers heard. This was adapted according to the principles adopted in the Dichotic Digit Test ${ }^{(14)}$, consisting of disyllabic words that represent the numbers in Brazilian Portuguese, four, five, seven, eight and nine in the stage called dichotic/binaural integration.

3 - Competing dichotic listening (dissyllables): 10 sequences in which the child hears four dissyllable words, two in the right ear and two in the left, in such a way that the first word is isolated (noncompeting condition), the second and third are simultaneous (competing conditions in the right and left ears) and the last is isolated (noncompeting condition). The initial stimuli in the right and left ear is alternated at each presentation, thus alternating the initial side of the noncompeting condition. The child should repeat the four words in the correct order and later the answer will be selected on the computer screen by the child. The performance in the situation of dichotic listening in the competing condition was considered for analysis. This task was adapted according to the principles of the Staggered Spondee Word (SSW) Test in Brazilian Portuguese ${ }^{(15)}$.

4 - Auditory closure: 10 sequences per ear in which the child hears an acoustically modified word and must recognize it in the options displayed on the screen. The options are composed of four word options and the "other word" option. The word sequences were different in each ear. The modifications were produced using the Gargle effect option of EarMix software (CTS Informática). The test was adapted according to the principles of the Speech-in-Noise Test, with the presentation of 25 monosyllables using white noise $^{(16)}$.

5 - Figure-Ground (ipsilateral): 10 sequences per ear in which the child hears a story and concomitantly a meaningless sentence. The child should ignore the story and indicate the sentence corresponding to the target message. Five sentences are presented in a signal-to-noise ratio of $-10 \mathrm{~dB}$, considering "noise" as the story and signal as the target sentence of the test, and five sentences are in the signal-to-noise ratio of $-15 \mathrm{~dB}$. The test was adapted according to the test Identification of Pediatric/Synthetic Sentences with Ipsilateral Competing Message - PSI/SSI ${ }^{(17)}$.

6 - Temporal Resolution: Initially the child becomes familiar with the stimuli of the activity, which may be a single stimulus (whistle) or a double sequence, named double sound (two stimuli with gaps between them which may vary from $2 \mathrm{~ms}$ to $5 \mathrm{~ms}, 10 \mathrm{~ms}, 15 \mathrm{~ms}$ and $20 \mathrm{~ms}$ ). The stimulus frequency used was $1000 \mathrm{~Hz}$. In each presentation the child hears a sequence of six sounds, between single and doubles, and is asked to count how many double sounds are perceived. At the end the child says or indicates the answer on the screen. The number of gaps may range from 1 to 5 double stimuli in each sequence. This test was adapted according to the principles of the Random Gap Detection Test (RGDT) ${ }^{(18)}$ to detect temporal acuity threshold.

7 - Temporal Ordering (pitch): Initially the child listens to the stimuli of the activity, consisting of a low-pitch stimulus (call LOW-L) of $800 \mathrm{~Hz}$ and a high-pitch stimulus (called HIGH-H) of $1300 \mathrm{~Hz}$. The stimuli are in the same range of equal-loudness $^{(19)}$. The activity consists of 10 sequences of three combinations of these pure tones lasting $250 \mathrm{~ms}$, such as LLH, HHL, HLH, LHL, LHH and HLL, and a silence interval between them lasting $200 \mathrm{~ms}$. Half of the sequences are in the right ear and half in the left ear. The child should listen to and name the correct sequence. The test was adapted according to the principles of the Pitch Pattern Test ${ }^{(20)}$.

8 - Temporal ordering (duration): Initially the child listens to the stimuli of the activity, consisting of a pure tone of $900 \mathrm{~Hz}$ lasting 500 milliseconds (LONG-L) and another lasting 
200ms (SHORT-S). The activity consists of 10 sequences of three combinations of these pure tones with silence intervals between them of $250 \mathrm{~ms}$, such as LLS, SSL, LSL, SLS, SLL and LSS. Half of the sequences are in the right ear and half in the left ear. The child should listen to and name the correct sequence. The test was adapted according to the principles of the Duration Pattern Test ${ }^{(20)}$.

The program offers the possibility of computerized management of collected data, which enabled the creation of the database to store the outcomes, and also allows the visualization of the performance of each task in terms of percentage and/or number of correct answers right after the task or at the end of the screening.

\section{Administration procedures}

The audBility program was administered in a quiet room provided by the school, using a LG desktop computer equipped with a Panasonic RP-HC720 noise canceling headset. The computer's volume mixer remained fixed at 50\%. After the previous procedures in order to confirm the inclusion and exclusion criteria, the SAB-based self-perception questionnaire previously described was applied. The questions were displayed on the computer screen and the researcher read them together with the child and explained the situation when necessary. The researcher clicked on the child's desired response on the screen.

Before the beginning of each listening task, the program displays a training screen for the child to understand the activity. Half the children started the tasks with the right ear and half with the left ear and the researcher clicked on the answers produced by the children.

\section{Analysis of results}

Based on the data obtained from the questionnaire, descriptive statistics were calculated with measures of dispersion referring to the total final score (mean and standard deviation). The percentage of correct answers (mean, median and standard deviation) of each listening task was calculated, as well as performance by ear, when possible. The cutoff score of the studied sample for each task and questionnaire was calculated based on the criterion of mean performance subtracted from one standard deviation. The paired student t-test was used to compare performance between the right and left ears, except for the sound localization and temporal resolution tasks. A 0.05 level of significance was used and significant data were highlighted in bold.

\section{RESULTS}

Regarding the self-perception questionnaire, the mean score obtained was $44.75 \pm 6.3$ points. Considering the mean subtracted from one standard deviation, the cutoff score of the present sample was 38.45 points.

Table 1 shows the performance data in the questionnaire (percentage and score) as well as the performance of the sample in each listening task, considering the percentage of correct answers (mean, median and standard deviation) and the sample cutoff score.

\section{Final version of audBility}

The adjustments and improvements made from the results herein presented were used to design the final version of audBility to be validated in future research. For the final version it was

Table 1. Sample performance in each hearing task $(n=43)$

\begin{tabular}{|c|c|c|c|c|c|}
\hline Tasks (\% correct answers) & $\mathrm{N}$ & Mean & Median & $\begin{array}{l}\text { Standard } \\
\text { Deviation }\end{array}$ & P-value \\
\hline Questionnaire (Score) & 43 & 44.75 & 45.5 & 6.3 & \\
\hline Sound localization & 43 & $85.8 \%$ & $90.0 \%$ & 9.8 & \\
\hline DDT- integration stage LE & 43 & $94.8 \%$ & $95.0 \%$ & 5.2 & \\
\hline Comp. Dichotic Listening RE & 43 & $74.0 \%$ & $70.0 \%$ & 16.6 & 0.323 \\
\hline Auditory closure LE & 43 & $84.2 \%$ & $90.0 \%$ & 11.8 & \\
\hline Figure-Ground RE-10 & 43 & $94.0 \%$ & $100.0 \%$ & 12.8 & \\
\hline Figure-Ground RE -15 & 43 & $97.7 \%$ & $100.0 \%$ & 7.8 & \\
\hline Figure-Ground LE -10 & 43 & $91.2 \%$ & $100.0 \%$ & 18.2 & \\
\hline Figure-Ground LE -15 & 43 & $96.7 \%$ & $100.0 \%$ & 7.5 & \\
\hline Temporal ordering (pitch)RE & 43 & $72.6 \%$ & $80.0 \%$ & 24.3 & 0.594 \\
\hline Temporal ordering (pitch)LE & 43 & $70.2 \%$ & $80.0 \%$ & 26.3 & \\
\hline Temporal ordering (duration) RE & 43 & $68.8 \%$ & $80.0 \%$ & 25.9 & 0.003 \\
\hline Temporal ordering (duration) LE & 43 & $78.6 \%$ & $80.0 \%$ & 21.1 & \\
\hline
\end{tabular}

Caption: DDT = Dichotic Digit Test; Paired student t-test; RE = right ear; LE = left ear 
Chart 1. Screening modules according to age group

\begin{tabular}{|c|c|c|c|}
\hline \multicolumn{2}{|r|}{ Ages 9 to 12} & \multicolumn{2}{|r|}{ Ages 6 to 8} \\
\hline audBility task & Parameters & audBility task & Parameters \\
\hline Sound localization & 10 target situations: right, left, or above/behind & Sound localization & 10 target situations: right, left, or above/behind \\
\hline Binaural integration & $\begin{array}{c}4 \text { numbers presented concomitantly (two in the } \\
\text { right ear and two in the left ear). }\end{array}$ & $\begin{array}{c}\text { Binaural } \\
\text { integration }\end{array}$ & $\begin{array}{c}4 \text { numbers presented concomitantly (two in the } \\
\text { right ear and two in the left ear). }\end{array}$ \\
\hline $\begin{array}{l}\text { Figure-ground } \\
\text { (monoaural) }\end{array}$ & $\begin{array}{l}10 \text { sequences per ear: the child hears a story } \\
\text { and concomitantly a sentence referring to the } \\
\text { image. He or she must indicate the sentence. }\end{array}$ & $\begin{array}{l}\text { Figure-ground } \\
\text { (monoaural) }\end{array}$ & $\begin{array}{l}10 \text { sequences per ear: the child hears a story } \\
\text { and concomitantly a sentence referring to the } \\
\text { image. He or she must indicate the image. }\end{array}$ \\
\hline $\begin{array}{l}\text { Auditory closure } \\
\text { (monoaural) }\end{array}$ & $\begin{array}{c}10 \text { sequences per ear: the child hears an } \\
\text { acoustically modified word and must recognize } \\
\text { the written word in the options displayed on the } \\
\text { screen. }\end{array}$ & Auditory closure & $\begin{array}{l}10 \text { sequences per ear: the child hears an } \\
\text { acoustically modified word and must recognize } \\
\text { the word in the images displayed on the screen. }\end{array}$ \\
\hline $\begin{array}{l}\text { Temporal } \\
\text { resolution }\end{array}$ & $\begin{array}{l}\text { Single } 1000 \mathrm{~Hz} \text { stimuli (whistle) with varying gaps } \\
\text { between them of } 20 \mathrm{~ms}, 15 \mathrm{~ms}, 10 \mathrm{~ms}, 6 \mathrm{~ms}, 4 \mathrm{~ms} \\
\text { and } 0 \mathrm{~ms} \text {. In each presentation the child listens } \\
\text { to a sequence of six sounds and is asked to } \\
\text { count how many he or she can perceive/hear. }\end{array}$ & $\begin{array}{l}\text { Temporal } \\
\text { resolution }\end{array}$ & $\begin{array}{c}\text { Single } 1000 \mathrm{~Hz} \text { stimuli (whistle) with varying gaps } \\
\text { between them of } 20 \mathrm{~ms}, 15 \mathrm{~ms}, 10 \mathrm{~ms}, 6 \mathrm{~ms}, 4 \mathrm{~ms} \\
\text { and } 0 \mathrm{~ms} \text {. In each presentation the child listens } \\
\text { to a sequence of six sounds and is asked to } \\
\text { count how many he or she can perceive/hear. }\end{array}$ \\
\hline $\begin{array}{l}\text { Temporal ordering } \\
\text { - duration }\end{array}$ & $\begin{array}{c}10 \text { sequences of three combinations of } \\
\text { pure tones of } 900 \mathrm{~Hz} / 500 \mathrm{~ms} \text { (LONG-L) and } \\
900 \mathrm{~Hz} / 200 \mathrm{~ms} \text { (SHORT-S). Time gaps between } \\
\text { the sequences of } 250 \mathrm{~ms} \text { (LLS, SSL, LSL, SLS, } \\
\text { SLL and LSS). }\end{array}$ & $\begin{array}{l}\text { Temporal ordering } \\
\text { - duration }\end{array}$ & 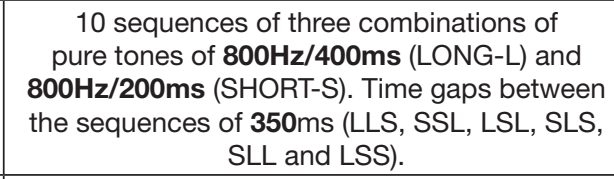 \\
\hline $\begin{array}{l}\text { Temporal ordering } \\
\text { - pitch }\end{array}$ & 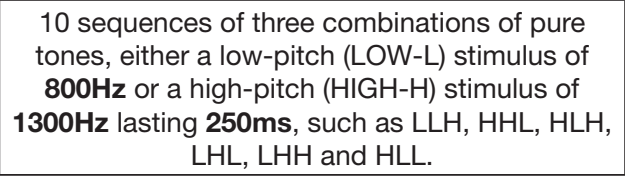 & $\begin{array}{c}\text { Temporal ordering } \\
\text { - pitch }\end{array}$ & 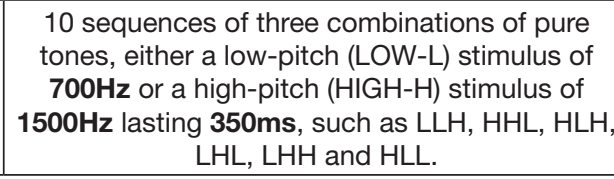 \\
\hline
\end{tabular}

Caption: $\mathrm{Hz}=\mathrm{Hertz} ; \mathrm{ms}=$ miliseconds

decided to separate two protocols/modules by age group, one for younger children aged 6 to 8 and another for the age group of 9 to 12 . Chart 1 presents the final version of each of the final audBility modules, the parameters of the listening activities and the adaptations that resulted in the module for younger children. On that module, the auditory tasks originally involving reading skills of words or sentences (figure-ground and closure) were replaced with figures.

Another adjustment to the program was the inclusion of more two versions of the self-perception questionnaire, that can be answered by parents or teachers, respectively (Annex 1).

\section{DISCUSSION}

The development of audBility represents an advance in the area of auditory processing screening in schoolchildren, favoring future research, especially regarding the interactive presentation of tasks with automatic data storage. The interactive and comprehensive proposal of the hearing skills is similar to another study, which developed a screening tool administered with native English-speaking children ${ }^{(8)}$. It should be emphasized that such a battery should not replace diagnostic evaluation. The inclusion of the self-perception questionnaire together with the listening tasks seems to be an important strategy to contribute to the identification of complaints and behaviors that may be linked to the risk of CAPD among schoolchildren.

The mean score obtained in the self-perception questionnaire was 44.75 , and taking into account the standard deviation of the sample, a cutoff score of 38.45 was obtained. Based on this data, five schoolchildren (11.6\%) scored below this cutoff, despite their good performance at school.

These findings may be considered close to the values found in a study using a similar tool ${ }^{(11)}$. In that study, which used the original $\mathrm{SAB}$, the authors suggest that final scores above 45 points are expected for the 8 to 11 age group. In addition, scores below 35 points (a standard deviation below the mean) would indicate a need auditory processing assessment and scores below 30 points would be suggestive of CAPD, requiring long-term monitoring ${ }^{(11)}$. In another similar study with European Portuguese-speaking children aged 10 to $13^{(12)}$ the questionnaire answered by parents also showed that scores below 46 points might suggest risk of CAPD, and this finding had to be analyzed together with other screening tests. For those authors, scores between 31-45 points suggest the need for formal evaluation and those below 30 points demonstrate a high risk of CAPD, with immediate referral being necessary. It is worth mentioning that although the cited studies corroborate the risk criterion for CAPD from the score above 45 points proposed by Nunes et al. ${ }^{(12)}$, the results of this study were obtained with a modified version of the questionnaire. Therefore, we emphasize the importance of further studies with the Brazilian pediatric population to validate this instrument and establish normative data based on a more significant sample.

For the final version of the program two new versions of the questionnaire will be included, one aimed at teachers and another at parents, based on the same questions.

In the listening tasks one can observe that in the sound localization activity, the average performance of $80 \%$ of correct 
answers was considered, that is, a maximum of two errors (20\%) as expected performance. Sound localization is understood to be a binaural phenomenon, since the central auditory nervous system (CANS) performs an accurate analysis of the acoustic cues and inter-aural differences of time and intensity of the stimulus to determine the position of the sound source. Such a skill, in the school setting, is important not only to determine the distance and position of the source, but is related to the phenomenon of binaural hearing, which favors sound perception with less effort due to the binaural summation effect ${ }^{(21)}$.

In the Dichotic Digit Test, which evaluates the skill of binaural integration, a minimum of $85 \%$ of correct answers in each ear was observed as expected performance. Evaluating the same skill, but based on performance in the task of Sequential Competing Dichotic Listening with disyllables, one may consider the minimum of $60 \%$ of correct answers in each ear in the competing condition as expected performance, with the presence of two inversions at most. Difficulties in the processes involved in dichotic listening may have important implications for speech recognition, especially in unfavorable environments such as competing background noise or speech signals, and may be an aggravating factor in difficulties related to reading and writing and a risk factor for poor academic performance ${ }^{(1,22)}$.

Given that the sample consisted of children with good school performance and absence of hearing complaints, the $60 \%$ performance rate in sequential competing dichotic listening compared with dichotic digit listening suggested a high degree of difficulty in this task as designed. Therefore, and considering the need to adjust the screening administration time to no more than 30 minutes in the school setting, it was proposed to remove the task of Sequential Competing Dichotic Listening, also in order to define the protocol for future audBility validation research.

In the auditory closure task, the test was randomly administered regarding beginning with the right or left ear and a greater variability of answers was observed considering both ears. The left ear had a statistically better performance compared to the right ear, which implies that the expected results in cutoff score based on the performance of these children are different per ear and indicate a minimum of $50 \%$ of right answers in the right ear and $70 \%$ in the left ear.

Despite the existence of studies suggesting a possible learning factor regarding the poorer results in the first ear tested compared to the second in closure tasks ${ }^{(23)}$, the difference in performance indicated a need to review the semantic and phonetic balance of the speech material used in this task. Initially, different words were used in each list, which may have favored the difference of results between the ears. Therefore, adjustments were made in the presentation of the word lists for the final version, in which the same words will make up the lists to be presented in the right and left ears, but in a different order.

In the auditory figure-ground task, a minimum of $80 \%$ of correct answers was found to be normal regarding the total scores of the right ear and left ear. Figure-ground skills are acknowledged as important to understand and recognize speech in noisy environments and to perform daily tasks, especially related to school life, such as reading in noisy environments or learning content in the classroom. In most schools learning occurs in the classroom with the presence of other competing stimuli (recreation noises, conversation among classmates, as well as rooms acoustically unfit to isolate external noise), and according to research such noises can reach up to approximately $90 \mathrm{~dB}^{(24,25)}$.

In the temporal resolution screening, the mean performance of children was $82.3 \%$, and given the standard deviation of 17.3 , we may consider the minimum of $60 \%$ of correct answers as expected performance, thus deemed a difficult task. Temporal Resolution (TR) is defined as the skill to detect time gaps between sound stimuli or the shortest time in which an individual is able to discriminate between two audible signals. Difficulties in TR may affect phonological processing and discrimination of tongue sounds and thus interfere with speech comprehension, especially at increased speed ${ }^{(26)}$.

The administered procedure did not enable the identification of a gap detection threshold. Rather, a result is obtained from the percentage of correct answers in the task. Some parameters contained in this task may partly justify the great variability of answers and the low mean performance. According to some authors' description of the mechanisms involved in gap detection tests, the task of perceiving two sounds as a single sound when the gap is not perceived seems to involve, besides temporal resolution, the binaural fusion mechanism, rendering the task even more complicated ${ }^{(27,28)}$. Moreover, in this study the task also required students to mentally count "double" stimuli, differentiating them from single ones, which involved memory and auditory attention and a greater cognitive demand than simple detection. Therefore, the temporal resolution task, despite its expected performance, was considered by most children to be hard to understand and was modified in the final version of the battery, involving single stimuli (whistle) with varying gaps between them of $20 \mathrm{~ms}, 15 \mathrm{~ms}, 10 \mathrm{~ms}, 6 \mathrm{~ms}, 4 \mathrm{~ms}$ and $0 \mathrm{~ms}$. In each presentation the child listens to a sequence of six sounds and is asked to count how many he or she can perceive/hear.

The average performance of the children in temporal ordering tasks made it possible to suggest a minimum of $50 \%$ of correct answers in the total score, in both pitch and duration. Temporal ordering is understood as a skill related to perceiving one or more auditory stimuli and distinguishing the order of in which acoustic events occur in time. Difficulties in this skill may still result in nonverbal learning impairment in the perception of acoustic aspects of speech at the suprasegmental level, such as intonation and rhythm ${ }^{(29)}$.

The administration of this battery suggested the need to create a specific module aimed at children under the age of nine, replacing words with images and including more playful tasks. The new module is under development and future research will be carried out. In the module being designed for younger children, it was suggested to modify the acoustic parameters of the pitch pattern test according to the children's version of the test produced by Auditec of St Louis, which presents 6s time gaps between the sequences, pure long $(500 \mathrm{~ms})$ and short $(250 \mathrm{~ms})$ tones, with an interval of $300 \mathrm{~ms}$ between tones, and frequency kept constant at $1000 \mathrm{~Hz}^{(30)}$. These parameters make the task more accessible to younger children, since it is a complex task involving hemispheric integration and maturation of the corpus 
callosum, responsible for the transfer of information from one hemisphere to the other ${ }^{(2)}$.

The authors believe that audBility has the potential to be used as a screening tool in the school environment, addressing the complexity of auditory skills involved in CAP. From the definition of the new screening protocol in audBility, new studies will be carried out to analyze the questionnaires as a complementary method in auditory screening and potential in the qualitative analysis of auditory behavior, comparing the perceptions of children, as well as of their parents and teachers. In addition, the specific modules for each age group will be administered for the validation of audBility, increasing the sample and making comparisons with the diagnostic battery.

\section{CONCLUSION}

From the analysis of the outcomes obtained, we concluded that adjustments were necessary in the initial version of the online audBility program. Therefore, such adjustments were proposed to reduce the screening protocol and administration time, as well to adapt the parameters of auditory tasks to the level of complexity appropriate for children. In addition, it was suggested to create two modules, one with images that do not require reading and writing to be administered to children under 9 years old or who are not yet fully literate and another module for children over 9 years old with tasks involving written words.

\section{ACKNOWLEDGEMENTS}

Programa Nacional de Pós-Doutorado CAPES - PNPD/ CAPES. À Fundação de Amparo à Pesquisa do Estado de São Paulo - FAPESP \#2016/23718-2. The authors thank Espaço da Escrita - Pró-Reitoria de Pesquisa - UNICAMP - for the language services provided. We thank the audiology and speech therapists Ingrid Gielow, Leticia Reis Borges and Diana Faria for the conception and creation of audBility and the version of the questionnaire used in this study.

\section{REFERENCES}

1. American Speech-Language-Hearing Association. Central auditory processing disorders - Position statement - The role of the audiologist [Internet]. Rockville: ASHA; 2005 [citado 2017 Nov 14]. Available from: www.asha.org/policy

2. Chermak GD, Musiek FE. Neurological substrate of central auditory processing deficits in children. Curr Pediatr Rev. 2011;7(3):241-51. http:// dx.doi.org/10.2174/157339611796548393.

3. Bellis TJ. Neuromaturation and neuroplasticity of the auditory system. In: Bellis TJ, editor. Assessment and management of central auditory processing disorders in the educational setting - From science to practice. Canada: Thomson Deliviar Learning; 2003. p. 103-39.

4. AAA: American Academy of Audiology Clinical. Practice guidelines: diagnosis, treatment and management of children and adults with central auditory processing disorder [Internet]. Reston: AAA; 2010 [citado 2017 Nov 14]. Available from: www.audiology.org/publications-resources/ document-library/central-auditory-processing-disorder

5. Keith RW. Development and standardization of SCAN-C test for auditory processing disorders in children. J Am Acad Audiol. 2000;11(8):438-45. PMid:11012239.
6. Moore DR, Ferguson MA, Edmondson-Jones AM, Ratib S, Riley A. Nature of auditory processing disorder in children. Pediatrics. 2010;126(2):382-90. http://dx.doi.org/10.1542/peds.2009-2826. PMid:20660546.

7. Yathiraj A, Maggu AR. Screening test for auditory processing (STAP): a preliminary report. J Am Acad Audiol. 2013;24(9):867-78. http://dx.doi org/10.3766/jaaa.24.9.10. PMid:24224993.

8. Barker MD, Purdy SC. An initial investigation into the validity of a computer-based auditory processing assessment (Feather Squadron). Int J Audiol. 2016;55(3):173-83. http://dx.doi.org/10.3109/14992027.2015.1 074734. PMid:26329098.

9. Skarzynski PH, Wlodarczyk AW, Kochanek K, Pilka A, Jedrzejczak WW, Olszewski L, et al. Central auditory processing disorder (CAPD) tests in a school-age hearing screening programme - analysis of 76,429 children. Ann Agric Environ Med. 2015;22(1):90-5. http://dx.doi. org/10.5604/12321966.1141375. PMid:25780835.

10. CISG: The Canadian Interorganizational Steering Group for Speech Language Pathology and Audiology. Canadian guidelines on auditory processing disorders in children and adults: assessment and intervention [Internet] Quebéc: OOAQ; 2012 [citado 2017 Nov 14]. Available from: http://www. ooaq.qc.ca/publications/doc-documents/Canadian_Guidelines_EN.pdf

11. Schow RL, Seikel JA. Screening for (central) auditory processing disorder. In: Chermak G, Musiek F, editors. Handbook of (central) auditory processing disorder: auditory neuroscience and diagnosis. San Diego: Plural Pub; 2006. p. 137-61.

12. Nunes CL, Pereira LD, Carvalho GS. Scale of Auditory Behaviors e testes auditivos comportamentais para avaliação do processamento auditivo em crianças falantes do português europeu. CoDAS. 2013;25(3):209-15. http:// dx.doi.org/10.1590/S2317-17822013000300004. PMid:24408330.

13. Pereira LD, Schochat E. Processamento auditivo central: abordagem passo a passo. In: Pereira LD, Schochat E, editores. Processamento auditivo central: manual de avaliação. São Paulo: Lovise; 1997. p. 49-60.

14. Santos MFC, Pereira LD. Escuta com dígitos. In: Pereira LD, Schochat E. Processamento auditivo central: Manual de avaliação. São Paulo: Lovise; 1997. p. 147-9.

15. Borges ACLC. Adaptação do teste SSW para a língua portuguesa: nota preliminar. Acta Awho. 1986;5:38-40

16. Mangabeira-Albernaz PL. Logoaudiometria. In: Pereira LD, Schochat E, editores. Processamento auditivo central: manual de avaliação. São Paulo: Lovise; 1997. p. 37-42.

17. Ziliotto KN, Kalil DM, Almeida CIR. PSI em Português. In Pereira DL, Schochat E. Processamento Auditivo Central - manual de avaliação. São Paulo: Lovise; 1997. p.113-28.

18. Random Gap Detection Test- Expanded (RGDT-E). Keith RW. St. Louis: Auditec, 2002.

19. Fletcher H, Munson WA. Loudness, its definition, measurement and calculation J Acoust Soc Am. 1993;5(2):82-108. http://dx.doi.org/10.1121/1.1915637.

20. Musiek FE, Baran JA, Pinheiro ML. Behavioral and electrophysiological test procedures. In: Musiek FE, Baran JA, Pinheiro ML. Neuroaudiology: case studies. San Diego: Singular Publishing Group; 1994. p. 7-28.

21. Nishihata R, Vieira MR, Pereira LD, Chiari BM. Processamento temporal, localização e fechamento auditivo em portadores de perda auditiva unilateral. Rev Soc Bras Fonoaudiol. 2012;17(3):266-73. http://dx.doi.org/10.1590/ S1516-80342012000300006.

22. Bailey PJ, Snowling MJ. Auditory processing and the development of language and literacy. Br Med Bull. 2002;63(1):135-46. http://dx.doi. org/10.1093/bmb/63.1.135. PMid:12324389.

23. Caporali SA, Silva JA. Reconhecimento de fala no ruído em jovens e idosos com perda auditiva. Rev Bras Otorrinolaringol. 2004;70(4):525-32. http://dx.doi.org/10.1590/S0034-72992004000400014.

24. Garcia VL, Pereira LD, Fukuda Y. Atenção seletiva: PSI em crianças com distúrbio de aprendizagem. Rev Bras Otorrinolaringol. 2007;73(3):404-11. http://dx.doi.org/10.1016/S1808-8694(15)30086-0.

25. Lacerda ABM, Gonçalves CGO, Lacerda G, Lobato DCB, Santos L, Moreira AC, et al. Childhood Hearing Health: Educating for Prevention of 
Hearing Loss. Int Arch Otorhinolaryngol. 2015;19(1):16-21. http://dx.doi. org/10.1055/s-0034-1387810. PMid:25992146.

26. Shinn JB. Temporal processing: the basics. Hear J. 2003;56(7):52. http:// dx.doi.org/10.1097/01.HJ.0000292557.52409.67.

27. Lister JJ, Koehnke JD, Besing JM. Binaural gap duration discrimination in listeners with impaired hearing and normal hearing. Ear Hear. 2000;21(2):14150. http://dx.doi.org/10.1097/00003446-200004000-00008. PMid:10777021.

28. Amaral MIR, Martins PFM, Colella-Santos MF. Temporal resolution: assessment procedures and parameters for school-aged children. Braz J Otorhinolaryngol. 2013;79(3):317-24. http://dx.doi.org/10.5935/18088694.20130057. PMid:23743747.
29. Amaral MIR, Casali RL, Boscariol M, Lunardi LL, Guerreiro MM, ColellaSantos MF. Temporal auditory processing and phonological awareness in children with benign epilepsy with centrotemporal spikes. BioMed Res Int. 2015;2015:256340. http://dx.doi.org/10.1155/2015/256340. PMid:25685775.

30. Auditec de Saint Louis. Evaluation manual of pitch pattern sequence and duration pattern sequence. Saint Louis: Auditec; 1997.

\section{Author contributions}

MIRA took part in data planning, collection, analysis and interpretation; $N G C$ and MFCS took part in data analysis and interpretation; MIRA, NGC and MFCS were responsible for drafting the article; MFC, as supervisor, conceived the project; MIRA was responsible for submitting the paper. 
Annex 1. Questionnaires

\section{SELF-PERCEPTION QUESTIONNAIRE - Child}

Date:

Child's name:

Grade:

Please answer based on your experience.

If you are not sure, refer to comments you have heard about yourself.

Each question should be evaluated based on how often the situation occurs or not.

1. You are in a classroom or environment where people are talking.

Do you have difficulty hearing or understanding what the teacher is saying?

FREQUENT OFTEN SOMETIMES SELDOM NEVER

2. The teacher or a person is speaking with you very fast.

Do you have difficulty understanding what the teacher says?

FREQUENT OFTEN SOMETIMES SELDOM NEVER

3. The teacher or a person is giving you oral instructions (explanations).

Do you have difficulty following the oral instructions?

FREQUENT OFTEN SOMETIMES SELDOM NEVER

4. The teacher or a person is talking to you in a quiet environment.

Do you have difficulty hearing and understanding clearly the words without exchanging any letters?

FREQUENT OFTEN SOMETIMES SELDOM NEVER

5. When the teacher or a friend is talking to you.

Do you feel that sometimes you hear well and sometimes not?

FREQUENT OFTEN SOMETIMES SELDOM NEVER

6. You are in the classroom or school yard and someone calls out your name.

Do you have difficulty noticing where the sound comes from?

FREQUENT OFTEN SOMETIMES SELDOM NEVER

7. The teacher or a person is talking to you.

Do you ask them to repeat what they said?

FREQUENT OFTEN SOMETIMES SELDOM NEVER

8. You are in the classroom.

Do you get easily distracted?

FREQUENT OFTEN SOMETIMES SELDOM NEVER

9. Last year at school.

Did you have learning difficulties?

FREQUENT OFTEN SOMETIMES SELDOM NEVER

10. You are doing an assignment.

Do you have difficulty focusing?

FREQUENT OFTEN SOMETIMES SELDOM NEVER

11. When you are in the classroom or at home.

Do people say you daydream or are inattentive?

FREQUENT OFTEN SOMETIMES SELDOM NEVER

12. When you are at school or at home.

Are you disorganized?

FREQUENT OFTEN SOMETIMES SELDOM NEVER

SELF-PERCEPTION QUESTIONNAIRE - PARENTS

Date:

Child's name:

Grade:

Name of parent or guardian: 
Please answer based on your observation of your child's behavior.

If you are not sure, refer to any comments you have heard about the situation.

Each question should be evaluated based on how often the situation occurs or not.

1. When your child is in an environment where people are talking.

Does he/she have difficulty hearing or understanding what people are saying?

FREQUENT OFTEN SOMETIMES SELDOM NEVER

2. If you talk too fast with your child.

Does he/she have difficulty understanding what you say?

FREQUENT OFTEN SOMETIMES SELDOM NEVER

3. When you give your child oral instructions (explanations).

Does he/she have difficulty following oral instructions?

FREQUENT OFTEN SOMETIMES SELDOM NEVER

4. If you are talking to your child in a quiet environment.

Does he/she have difficulty hearing and understanding clearly the words without exchanging any letters?

FREQUENT OFTEN SOMETIMES SELDOM NEVER

5. When you are talking to your child.

Do you feel that he/she sometimes hears well and sometimes not?

FREQUENT OFTEN SOMETIMES SELDOM NEVER

6. When your child is called by his/her name in a spacious environment.

Does he/she have difficulty noticing where the sound comes from?

FREQUENT OFTEN SOMETIMES SELDOM NEVER

7. When you are talking to your child.

Does he/she ask you to repeat what you said?

FREQUENT OFTEN SOMETIMES SELDOM NEVER

8. When your child is at home or in other environments.

Does he/she get distracted easily?

FREQUENT OFTEN SOMETIMES SELDOM NEVER

9. Last year at school

Did your child have learning difficulties?

FREQUENT OFTEN SOMETIMES SELDOM NEVER

10. When your child is doing homework.

Does he/she have difficulty focusing?

FREQUENT OFTEN SOMETIMES SELDOM NEVER

11. When your child is at home.

Do you think he/she daydreams or is inattentive?

FREQUENT OFTEN SOMETIMES SELDOM NEVER

12. When your child is home.

Is he/she disorganized?

FREQUENT OFTEN SOMETIMES SELDOM NEVER

SELF-PERCEPTION QUESTIONNAIRE - TEACHERS

Date:

Child's name:

Grade:

Teacher: 
Please answer based on your observation of your student's behavior.

If you are not sure, refer of any comments you have heard about the situation.

Each question should be evaluated based on how often the situation occurs or not.

1. When your student is in an environment where people are talking.

Does he/she have difficulty hearing or understanding what people are saying?

FREQUENT OFTEN SOMETIMES SELDOM NEVER

2. If you talk too fast with your student.

Does he/she have difficulty understanding what you say?

FREQUENT OFTEN SOMETIMES SELDOM NEVER

3. When you give your student oral instructions (explanations).

Does he/she have difficulty following oral instructions?

FREQUENT OFTEN SOMETIMES SELDOM NEVER

4. If you are talking to your student in a quiet environment.

Does he/she have difficulty hearing and understanding clearly the words without exchanging any letters?

FREQUENT OFTEN SOMETIMES SELDOM NEVER

5. When you are talking to your student.

Do you feel that he/she sometimes hears well and sometimes not?

FREQUENT OFTEN SOMETIMES SELDOM NEVER

6. When your student is in the classroom or school yard and someone call out his/her name.

Does he/she have difficulty noticing where the sound comes from?

FREQUENT OFTEN SOMETIMES SELDOM NEVER

7. When you are talking to your student.

Does he/she ask you to repeat what you said?

FREQUENT OFTEN SOMETIMES SELDOM NEVER

8. When your student is in the classroom.

Does he/she get distracted easily?

FREQUENT OFTEN SOMETIMES SELDOM NEVER

9. Last year at school.

Did your student have learning difficulties?

FREQUENT OFTEN SOMETIMES SELDOM NEVER

10. When your student is working in the classroom.

Does he/she have difficulty focusing?

FREQUENT OFTEN SOMETIMES SELDOM NEVER

11. When your student is in the classroom.

Do you think he/she daydreams or is inattentive?

FREQUENT OFTEN SOMETIMES SELDOM NEVER

12. When your student is in the classroom.

Is he/she disorganized?

FREQUENT OFTEN SOMETIMES SELDOM NEVER 